\title{
química
}

\section{OBTENÇÃO DO BIODIESEL METÍLICO ATRAVÉS DA TRANSESTERIFICAÇÃO VIA CATÁLISE BÁSICA DO ÓLEO DE \\ COCO-DA-BAÍA (Cocos nucifera $\mathrm{L}$ )}

\author{
V. O. Lace' ${ }^{1}$ I. M. Fraga ${ }^{1}$, J. R. C. Fernandez ${ }^{1}$; C. R. Gonçalves ${ }^{1}$; \\ ${ }^{1}$ Instituto Federal de Educação, Ciência e Tecnologia de Mato Grosso - Campus Cáceres. Av. \\ dos Ramires, s/n-CEP: 78.200-000-Cáceres / MT, Brasil. \\ isabel.fraga@cas.ifmt.edu.br
}

\begin{abstract}
Resumo: O presente trabalho teve como objetivo principal a produção de biodiesel metílico através da reação de transesterificação via catálise básica, utilizando como matéria-prima alternativa ao óleo de soja comumente utilizado, o óleo de coco-da-baía (Cocos nucifera $\mathrm{L}$ ). $\mathrm{O}$ biodiesel foi caracterizado quanto ao seu índice de acidez, densidade, umidade, teor de éster, ponto de fulgor, glicerol (livre, total, mono, di e triglicerol) e porcentagem máxima de metanol. O óleo usado foi caracterizado por índice de acidez, índice de saponificação, ácidos graxos, densidade e umidade. Através destes resultados, verificou-se a qualidade do biocombustível obtido.
\end{abstract}

Palavras-chave: Biodiesel, cocos nucifera L, transesterificação.

Abstract: This study aimed to the methyl biodiesel production by transesterification reaction via alkaline catalysis, using as a raw material alternative to soybean oil commonly used, cocoda-baía oil (Cocos nucifera L). The biodiesel was characterized as to its acidity, density, humidity, ester content, flash point, glycerol (free, total, mono-, di- and triglycerides) and maximum percentage of methanol. The oil used was characterized by acid value, saponification number, fatty acids, density and humidity. Through these results, we verified the quality of the obtained biofuel.

Keywords: Biodiesel, Cocos nucifera L, transesterification.

\section{INTRODUÇÃO}

O potencial do uso dos biocombustíveis vem se mostrando promissor no mundo inteiro, destacando-se como um mercado que cresce de forma acelerada devido a vários fatores como, a contribuição ao meio ambiente e por ser fonte estratégica de energia renovável em substituição ao óleo diesel [1].

De acordo com a Lei 11.097 de 13/01/2005, o biodiesel pode ser definido como: "Biocombustível derivado de biomassa renovável para uso em motores a combustão interna com ignição por compressão ou para geração de outro tipo de energia que possa substituir parcial ou totalmente o uso de combustível de origem fóssil'"[2].

Atualmente, o Brasil desponta como uma grande potência no desenvolvimento de tecnologia para produção de substitutos para os derivados do petróleo, graças a sua extensão territorial, ao clima propício ao plantio de diversas culturas, e principalmente a sua biodiversidade. O biodiesel, no Brasil, hoje é visto como o principal substituto do óleo diesel derivado do petróleo[3]. 
O processo mais comumente utilizado para a produção do biodiesel, é o processo de transesterificação, pois o mesmo é relativamente simples e seu custo de produção é considerado acessível. As características físico-químicas dos ésteres de ácidos graxos (biodiesel) obtidos são muito semelhantes às do óleo diesel. A transesterificação consiste numa reação química na qual um éster é transformado em outro através da troca dos grupos alcóxidos. Na transesterificação de óleos vegetais, um triglicerídeo reage com um álcool na presença de um catalisador produzindo uma mistura de ésteres monoalquílico de ácidos graxos e glicerol [4].

A reação de transesterificação deve ser completa, acarretando ausência total de ácidos graxos remanescentes e o biocombustível deve ser de alta pureza, não contendo traços de glicerina, de catalisador residual ou de álcool excedente da reação. Entre as várias oleaginosas que se tem conhecimento na literatura, as que apresentam um alto teor de óleo na semente, são favoráveis para a produção de biodiesel. Dentre estas, pode-se destacar as sementes oleaginosas de soja, amendoim, girassol, babaçu, milho, canola (colza), mamona e algodão [5].

Atualmente a produção nacional de biodiesel utiliza quase que exclusivamente a soja para a produção de óleo, caracterizando-se como monocultura para a produção do combustível, portanto é imprescindível a pesquisa de outras matérias primas que sejam técnica e economicamente viáveis para a produção desse combustível.

Dentre muitas matérias-primas que podem ser avaliadas como potencial para a produção de Biodiesel, destaca-se o Cocos nucifera L, popularmente conhecido como coco-da-baía que reúne características potenciais para a produção de óleo, pois contêm elevados teores de acido láurico, substância muito usada na indústria de alimentos, cosméticos, sabões e na fabricação de álcool [6].

O coqueiro (Cocos Nucifera L.), originário do Sudeste asiático, foi introduzido no Brasil em 1553, onde se apresenta naturalizado em longas áreas da costa nordestina proporcionando abundante matéria-prima tanto para as agroindústrias regionais quanto para uso alimentício [7].

Na maioria dos países produtores, o Coco (Cocos nucifera L.) é utilizado para a produção do óleo. Considerando-se uma densidade de 160 plantas/ha, e uma produção de 100 frutos/planta/ano, utilizando coqueiros híbridos com espaçamento de $8,5 \mathrm{~m}$ de lado em triângulo, seria possível uma produção de 16.000 frutos/ha. Seu conteúdo em óleo na polpa é superior a $60 \%$, levando o que equivale a uma produção de 0,5 a 3 toneladas de óleo/ha [2]. Esse conteúdo em óleo é visivelmente superior quando comparado ao da soja, que apesar de ser referência no setor de biodiesel, o seu rendimento em volume de óleo por área plantada possui um teor de óleo de 0,2-0,4 toneladas de óleo/há [21].

Até então, existem poucos trabalhos desenvolvidos a partir do óleo de coco. O coqueiro é uma das principais oleaginosas de fácil adaptação ao nordeste brasileiro, boa parte da região africana e parte da Ásia; e com excelente desenvolvimento sob o clima tropical [3].

Diante do exposto, o presente estudo tem como objetivo produzir biodiesel metílico através da reação de transesterificação do óleo de coco-da-baía, utilizando um catalisador de caráter básico.

\section{MATERIAIS E MÉTODOS}

\section{Transesterificação metílica do óleo de coco-da-baía, via catálise básica}

O óleo de coco utilizado nesse estudo foi extraído no laboratório de química do Instituto Federal do Mato Grosso através do método de prensagem das amêndoas. Para a extração, foram utilizadas 100 unidades de frutos secos coletados no município de Cáceres os mesmos são da variedade gigante. $\mathrm{O}$ procedimento proporcionou a produção $4,2 \mathrm{~L}$ de óleo, portanto cada fruto produziu em média $42 \mathrm{ml}$ de matéria para a produção do biodiesel.

O biodiesel foi sintetizado a partir da reação de transesterificação do óleo de coco, juntamente com o metanol fornecido pela Labsint, utilizando uma razão molar álcool/óleo de 6:1. Como catalisador, foi utilizado o hidróxido de potássio $(\mathrm{KOH})$ fornecido pela Dinâmica, na 
proporção de $1 \%$ em relação a massa de óleo. A reação foi processada durante $1 \mathrm{~h}$, a uma faixa de temperatura que variou entre $75-80{ }^{\circ} \mathrm{C}$. Foram adicionados $300 \mathrm{~mL}$ de óleo de coco a um balão de fundo chato de $1000 \mathrm{~mL}$, posteriormente o óleo foi aquecido até atingir a temperatura de $80{ }^{\circ} \mathrm{C}$. Enquanto isso, em um bécher de $250 \mathrm{~mL}, 3 \mathrm{~g}$ de $\mathrm{KOH}$ foram adicionados a $300 \mathrm{~mL}$ de metanol e foram conduzidos a agitação, até completa dissolução. A mistura álcool/KOH foi então adicionada ao balão contendo o óleo aquecido para dar início a reação de transesterificação. A reação foi mantida durante $1 \mathrm{~h}$ em um banho-maria, a uma faixa de temperatura que variou entre $75-80^{\circ} \mathrm{C}$, sob constante agitação [8].

Transcorrido o tempo de $1 \mathrm{~h}$, a mistura foi transferida para um funil de separação, e deixada em repouso por $24 \mathrm{~h}$ para total separação de fases. A fase inferior era composta por glicerina bruta e a fase superior era composta pelo biodiesel. A figura 3 apresenta o funil de separação contendo as duas fases [8].

A seguir o biodiesel produzido foi submetido a etapa de lavagem dentro do funil de separação. Inicialmente foram adicionados $75 \mathrm{~mL}$ da solução aquosa de ácido clorídrico a 0,5\% $(\mathrm{v} / \mathrm{v})$, a mistura foi deixada em repouso por 15 minutos para completa separação de fases, a fase inferior foi descartada, esse processou se deu por duas vezes. Posteriormente foram adicionados $60 \mathrm{~mL}$ de solução saturada de cloreto de sódio $(\mathrm{NaCl})$ e, finalmente, com $600 \mathrm{~mL}$ de água destilada. A parte inferior foi descarta e aparte superior (biodiesel) foi submetida a verificação de pH para confirmação da ausência do catalisador básico no biodiesel. Para remoção dos traços de umidade o biodiesel foi filtrado utilizando-se sulfato de sódio anidro [8].

\section{Caracterização físico-química do biodiesel}

O biodiesel produzido foi caracterizado para posterior comparação com as exigências especificadas pela da ANP (Agência nacional de petróleo, gás natural e biocombustíveis). As análises foram realizadas em termos dos parâmetros de índice de acidez, massa específica a $20^{\circ} \mathrm{C}$, umidade e material volátil, ponto de fulgor, teor de ésteres, teor de metanol, glicerina livre, a glicerina total, monoglicerídeos, diglicerídeos e triglicerídeos. Os demais parâmetros estabelecidos pela ANP (tão importantes quanto os analisados no presente estudo) não puderam ser analisados devido a falta de equipamentos segundo as normas técnicas previamente estabelecidas.

As análises foram realizadas na Central analítica de Combustíveis-CEANC / Campus UFMT e determinadas de acordo com os itens descritos abaixo.

O índice de acidez (AC) foi determinado segundo Moretto e Alves e Esteves et al. [9][10]. Tanto o óleo de coco-da-baía quanto o biodiesel de óleo de coco foram analisados quanto a seu índice de acidez.

A determinação da umidade foi efetuada através do método de perdas por dessecação em estufa de acordo com o método AOCS Bc 2-49. Cerca de $5 \mathrm{~g}$ de cada amostra foram pesadas em cadinhos de porcelana e aquecidas a $130{ }^{\circ} \mathrm{C}$ em estufa. Após o aquecimento, as amostras foram imediatamente tampadas e resfriadas em dessecador até atingirem a temperatura ambiente e, em seguida, foram novamente pesadas [12].

Para a determinação da massa específica, utilizou-se um picnômetro, instrumento aplicado para determinação da densidade real de óleos. Anteriormente calibrou-se com água a temperatura ambiente, logo após verteu-se o óleo sobre o picnômetro até que transbordasse, encaixou-se a tampa e limpando completamente a fim de evitar interferência no resultado, pesou-se anotando o valor correspondente a pesagem, tanto vazio quanto cheio[2].

Os demais parâmetros especificados pela ANP para o biodiesel, foram analisados de acordo com as normas descritas na tabela 1. Para a caracterização do biodiesel foram investigados ainda, o teor de ésteres, o ponto de fulgor, o teor de metanol, a glicerina livre, a glicerina total combinada, que inclui mono-, di- e triglicerídeos.

$\mathrm{O}$ ponto de fulgor é um parâmetro muito importante quanto à segurança no armazenamento e no transporte, principalmente quando a transesterificação foi realizada com metanol que, além de altamente inflamável, apresenta elevada toxidez. 
A glicerina é um co-produto da reação de transesterificação de óleos e gorduras. A determinação da glicerina residual serve como parâmetro para avaliar a eficiência do processo de purificação do biodiesel [13].

A glicerina total combinada, que inclui mono, di e triglicerídeos, é proveniente da reação incompleta dos glicerídeos, logo, este é um importante parâmetro que pode ser utilizado para avaliar a eficiência da conversão de óleos e gorduras em biodiesel. A glicerina combinada pode ser calculada a partir das concentrações de mono, di e triglicerídeos, aplicando-se fatores de conversões individuais baseados na massa molar média dos ácidos graxos que participam da composição da matéria-prima [14]. A soma da concentração da glicerina livre com a glicerina combinada é denominada como glicerina total.

O teor de álcool no biodiesel pode ser utilizado também para avaliar o processo de purificação do biodiesel. $\mathrm{Na}$ análise, é empregado um cromatógrafo equipado com uma coluna capilar polar, utilizando um detector de ionização de chama. Uma fração da fase gasosa de um recipiente hermeticamente fechado, contendo a mostra em equilíbrio a $80{ }^{\circ} \mathrm{C}$, é então ser injetada no cromatógrafo, utilizando-se 2-propanol para calibração interna [11], [13].

\section{RESULTADOS E DISCUSSÃO}

Após a síntese, lavagem e purificação, o biodiesel produzido apresentou o aspecto límpido e incolor, correspondendo ao aspecto exigido pela resolução nº 12 de 2014 da ANP [11].

Os resultados da caracterização físico-química do biodiesel metílico de óleo de coco-dabaía, são descritos na tabela 1 .

\section{TABELA 1}

Observando os resultados da tabela 1, é possível notar que o biodiesel obtido apresentou uma acidez acima do recomendado pela ANP. Esse comportamento pode estar relacionado a presença de água ou ácido que não foram completamente removidos durante o processo de lavagem. Albuquerque [5] obteve biodiesel metílico de óleo de canola e também encontrou uma acidez acima do recomendado pela ANP, de $0,55 \mathrm{mg} \mathrm{KOH} / \mathrm{g}$ [15]. Um índice de acidez elevado influencia na hidrólise do biodiesel e na sua oxidação, e pode catalisar reações intermoleculares dos triacilglicerídeos, ao mesmo tempo em que afeta a estabilidade térmica do combustível na câmara de combustão [17].

Vale ressaltar que o valor antes permitido pela ANP para esse parâmetro era de $0,8 \mathrm{mg}$ $\mathrm{KOH} / \mathrm{g}$. De acordo com Lôbo et al. [13], o monitoramento da acidez no biodiesel é de grande importância durante a estocagem, na qual a alteração dos valores neste período pode significar a presença de água.

A massa específica encontrada nesse estudo para o biodiesel metílico de óleo de coco $\left(890 \mathrm{Kg} / \mathrm{m}^{3}\right)$, encontra-se dentro da especificação descrita pela ANP [11]. De acordo com Lôbo et al., [13], a massa específica do biodiesel está diretamente ligada com a estrutura molecular das suas moléculas. Quanto maior o comprimento da cadeia carbônica do alquiléster, maior será a massa específica, no entanto, este valor decrescerá quanto maior forem o número de insaturações presentes na molécula. A presença de impureza também poderá influenciar na massa específica do biodiesel como, por exemplo, o álcool ou substâncias adulterantes.

A presença de metanol no biodiesel, está intimamente ligada ao processo de purificação do mesmo. Os resultados mostram que, não foi encontrada, nenhuma porcentagem mássica de metanol no biodiesel analisado, isso mostra que todo excesso de metanol foi eliminado no processo de lavagem.

De acordo com Knothe et al., [4], teores residuais de álcool no biodiesel podem resultar um efeito na diminuição do ponto de fulgor.

$\mathrm{O}$ percentual de ésteres verificado pela análise encontra-se ligeiramente inferior ao mínimo exigido pela ANP que é de 96,5\%. Esse teor de éster abaixo do limite mínimo da ANP, nesse estudo não está relacionado com a reação incompleta dos glicerídeos, visto que os teores 
de glicerol livre, total mono, di e trigliceróis, estiveram sempre abaixo do limite máximo exigido pela ANP [11]. De acordo com Lobo et al., [13], a glicerina combinada, que inclui mono, di e triglicerídeos, é proveniente da reação incompleta dos glicerídeos, logo, este é um importante parâmetro que pode ser utilizado para avaliar a eficiência da conversão de óleos e gorduras em biodiesel (ésteres). No caso do presente trabalho, é provável que o teor de éster abaixo do limite mínimo da ANP esteja relacionado com a reação indesejável de saponificação devido a porcentagem de ácidos graxos livres (AGL) presente no óleo de coco que era de 0,60 $\%$. Para gorduras com teor de AGL entre 0,5 e $4 \%$, a perda de catalisador que acompanha a saponificação durante a transesterificação alcalina é suficiente para comprometer a eficiência do processo [4]. É possível que parte do catalisador adicionado tenha sido desviado para a produção de sabões que foram eliminados durante o processo de lavagem. Neste caso, uma neutralização prévia da acidez presente no óleo poderia reduzir a possibilidade da formação de sabões.

Em temperaturas maiores que $60^{\circ} \mathrm{C}$, óleos refinados na razão molar de 6:1 álcool/óleo, fornecem rendimentos satisfatórios de ésteres metílicos em tempos reacionais de $1 \mathrm{~h}$. No entanto, quando se trata de óleos brutos, nessas mesmas condições $\left(60^{\circ} \mathrm{C}\right.$. $1 \mathrm{~h}$ e razão $\left.6: 1\right)$, o rendimento em ésteres é reduzido [4].

Diante disso, é possível que o aumento da conversão de óleo em ésteres seja favorecido com o aumento na razão molar álcool:óleo [4], [8] e [12]. Pode ser que sejam necessários também, maiores tempos reacionais ou maiores temperaturas para uma maior conversão.

A análise de glicerina livre no biodiesel comprovou a eficiência da purificação, uma vez que os resultados obtidos atendem a legislação que estabelece uma tolerância de, no máximo, $0,02 \%$ de glicerina livre no biodiesel [19]. Apesar de a glicerina ser um produto indesejável na reação de transesterificação pode ser um produto de alto valor comercial, dada sua ampla aplicação industrial (especialmente na indústria de cosméticos), assim tem-se além do biodiesel a glicerina como produto comercial [20]. Altas concentrações de glicerina no biodiesel provocam problemas de armazenamento, pois quando o biodiesel é misturado com o diesel de petróleo, observa-se a separação da glicerina nos tanques de estocagem. Problemas como formação de depósitos, entupimento dos bicos injetores do motor e emissões de aldeídos também estão relacionados com a alta concentração da glicerina no biodiesel. A glicerina livre residual pode ser facilmente eliminada através de lavagens do biodiesel. Embora seja praticamente insolúvel no biodiesel, a glicerina pode ser encontrada dispersa na forma de gotículas [13].

Os resultados para análise de umidade e material volátil evidenciam a presença de água no biodiesel final. A água, além de promover a hidrólise do biodiesel resultando em ácidos graxos livres, também está associada à proliferação de micro-organismos, corrosão em tanques de estocagem com deposição de sedimentos [13]. Essa presença de água encontrada no biodiesel pode corroborar a alta acidez do mesmo.

O ponto de fulgor do biodiesel produzido apresentou-se acima do valor mínimo exigido pela ANP, $114,2{ }^{\circ} \mathrm{C}$, o que indica um excelente resultado visto que o ponto de fulgor é a temperatura mínima onde é observada a liberação de vapores de um líquido, em quantidade suficiente para forma uma mistura inflamável com o ar [11]. Para o biodiesel, os valores de ponto de fulgor são, consideravelmente, mais elevados que os valores encontrados para o diesel mineral. Um alto ponto de fulgor, favorece o transporte e armazenamento do produto final, tornando-o um material menos inflamável, aumentando assim sua segurança durante o manuseio.

Diante dos resultados, a transesterificação do biodiesel metílico via catálise básica produzido a partir do óleo de coco-da-baía, se mostrou promissora. É necessário portanto, que sejam investigadas algumas adequações em parâmetros como tempo reacional, razão molar e temperatura para aumentar a conversão de óleo em ésteres metílicos. Em relação a qualidade do biodiesel produzido, a investigação dos demais parâmetros estabelecidos pela ANP também se faz necessária a fim de validar a matéria-prima alternativa como uma matéria-prima promissora para a produção de biodiesel metílico. 
Vale salientar que a matéria-prima é muito superior a soja em relação ao teor de óleo e que o método de extração utilizado nesse trabalho, não utilizou nenhum tipo de solvente orgânico o que tornaria o processo mais caro e menos sustentável, visto que a recuperação destes solventes é um processo caro e difícil e a disposição desses solventes deve ser cautelosa e deve também obedecer às normas específicas de disposição de resíduos de cada produto.

\section{CONCLUSÕES}

O biodiesel metílico produzido via catálise básica se apresentou límpido e satisfatório em relação às normas da ANP para oito das onze propriedades analisadas. O resultado não conforme estava apenas na acidez ao final do processo, e no teor de éster um pouco abaixo do valor especificado. Diante do exposto, a transesterificação do biodiesel metílico via catálise básica produzido a partir do óleo de coco-da-baía, se mostrou promissora. É necessário portanto, que sejam investigadas algumas adequações em parâmetros como tempo reacional, razão molar e temperatura para aumentar a conversão de óleo em ésteres metílicos. Em relação a qualidade do biodiesel produzido, a investigação dos demais parâmetros estabelecidos pela ANP também se faz necessária a fim de validar a matéria-prima alternativa como uma matéria-prima promissora para a produção de biodiesel metílico.

\section{REFERÊNCIAS}

[1] M. A. M. F. MELO. Avaliação das Propriedades de Óleos Vegetais visando a Produção de Biodiesel. Dissertação de Mestrado em Química, Universidade Federal da Paraíba, UFPB, João Pessoa, 2010.

[2] G. S. ARAÚJO. Produção de Biodiesel a partir do Óleo do Coco (coco nuficera L.). Dissertação de Mestrado em Engenharia Química, Universidade Federal do Rio Grande do Norte, UFRN, Natal, 2008.

[3] A. P. ALMEIDA. Etanólise do óleo de coco: estudo das variáveis de processo. Dissertação DE Mestrado em Engenharia Química, Universidade Federal de Alagoas, UFAL, Alagoas, 2010.

[4] Knothe, G.; Gerpen, J. V.; Krahl, J.; Ramos, L. P. Manual do Biodiesel, $5^{\text {th }}$ ed., Edgard Blücher: São Paulo, 2006.

[5] G. A. Albuquerque. Obtenção e caracterização Físico-química do Biodiesel de óleo de Canola (Brassica napus). Dissertação de Mestrado em Química, Universidade Federal da Paraíba,UFPB, João Pessoa, 2006.

[6] Balachandran, F. M.; Arumughan, C.; Mathew, A. G.; J. Am. Oil Chem. Soc. 1985, 62, 1583.

[7] Ferreira, J. M. S.; Wareick, D. R. N.; Siqueira, L. A. Cultura do coqueiro no Brasil. Embrapa-SPI. Aracaju, 1994; Sobral, J. P.

[8] Geris, R.; Santos, N. A. C.; Amaral, B. A.; Maia, I. S.; Castro, V. D.; Carvalho, J. R. M.; Quím. Nova 2007, 30,1369.

[9] Esteves, W.; Gonçalves, L.; Arellano, D. B. Compilação da Metodologia Padrão Alemã para análise de gorduras e outros lipídeos. FEA, Campinas, 1995.

[10] Moretto, E.; AlveS, R. Óleos e Gorduras Vegetais, Editora da UFSC, Florianópolis, 1986. 
[11]http://nxt.anp.gov.br/nxt/gateway.dll/leg/resolucoes_anp/2012/maio/ranp\%2014\%20\%202012.xml, acessada em maio de 2013.

[12] B. S. Moura. Transesterificação Alcalina de Óleos Vegetais Para Produção de Biodiesel: Avaliação Técnica e Econômica. Dissertação de Mestrado em Engenharia Química, Universidade Federal Rural do Rio de Janeiro, Brasil, UFRRJ, Seropédica, 2010.

[13] Lôbo, P. I.; Costa, S. L.; Cruz, R. S.; Quim. Nova, 2009, 32, 1596.

[14] Mittelbach, M.; Bioresour. Technol. 1996, 56, 7; Lôbo, P. I.; Costa, S. L.; Cruz, R. S.; Quim. Nova 2009, 32, 1596.

[15] Machado, G. C.; Chaves, J. B. P.; Antoniassi, R.; Rev. Ceres (Impr.) 2006, 53, 463.

[16] Araújo, F. D. S.; Chaves, M. H.; Araújo, E. C. E.; Resumos do $1^{\circ}$ Congresso Internacional de Agroenergia e Biocombustiveis - Energia de Resultados, Teresina, Brasil, 2007; Gonçalves, A.; Soares, J.; Brasil, A. N.; Nunes, D. L. Resumos do $3^{\circ}$ Congresso da rede brasileira de tecnologia de biodiesel, Brasília, Brasil, 2009.

[17] Souza,C. D. R.; Chaar, J. S.; .; Souza, R. C. R.; Jeffreys, M. F.; Souza, K. S.; Costa, E. J. C.; Santos, J. C.; Acta (Amazonica) 2009, 39, 383.

[18] Marques, M. V.; Naciuk, F. F.; Mello, A. M. de S.; Seibel, N. M.; Fontoura, L. A. M.; Quim. Nova 2010, 33, 978.

[19] Lima, J. R. O.; Silva, R. B.; Silva, C. C. M.; Santos, L. S. S.; Santos Jr, J. R.; Moura, E. M.; Moura, C. V. R.; Quim. Nova 2007, 30, 600.

[20] Froehner, S.; Leithold, J.; Lima Júnior, L. F.; Quim. Nova 2007, 30, 2016.

[21] HOLANDA, J. S. ALVES, M. C. S.; CHAGA, M. C. M. Cultivo do coqueiro no rio grande do norte. Governo do Estado Do Rio Grande do Norte.Rio Grande do Norte, 2009. 


\section{TABELA}

Tabela 1. Propriedades físico-químicas encontradas para o biodiesel metílico produzido via catálise básica a partir do óleo de coco-da-baía

\begin{tabular}{ccccc}
\hline Características & Unidade & $\begin{array}{c}\text { Biodiesel de } \\
\text { óleo de coco }\end{array}$ & $\begin{array}{c}\text { Limites } \\
\text { estabelecidos } \\
\text { pela ANP }\end{array}$ & MÉTODO \\
\hline Índice de Acidez & $\mathrm{mg} \mathrm{KOH} / \mathrm{g}$ & 0,77 & $\leq 0,50$ & {$[9]$ e [10] } \\
Densidade & $\mathrm{kg} / \mathrm{m}^{3}$ & 890 & $850-900$ & {$[2]$} \\
Umidade e matéria & $\%$ & 53,69 & - & AOC Bc 2-49 \\
volátil & & & & \\
Metanol ou Etanol & $\%$ em massa & 0,00 & $\leq 0,20$ & EN ISSO 14110 \\
Teor de éster & $\%$ em massa & 93,2 & $\geq 96,5$ & EN 14103 \\
Ponto de fulgor & ${ }^{\circ} \mathrm{C}$ & 114,2 & $\geq 100$ & ASTM D 93-C \\
Glicerol livre & $\%$ em massa & 0,00 & $\leq 0,02$ & EN 14105 \\
Glicerol total & $\%$ em massa & 0,08 & $\leq 0,25$ & EN 14105 \\
Monoglicerol & $\%$ em massa & 0,29 & $\leq 0,80$ & EN 14105 \\
Diglicerol & $\%$ em massa & 0,01 & $\leq 0,20$ & EN 14105 \\
Triglicerol & $\%$ em massa & 0,00 & $\leq 0,20$ & EN 14105 \\
\hline
\end{tabular}

